\title{
Article \\ Effect of Peptide Receptor Radionuclide Therapy in Combination with Temozolomide against Tumor Angiogenesis in a Glioblastoma Model
}

\author{
Sang Hee Lee ${ }^{1,2,+} \mathbb{D}$, Ji Young Choi ${ }^{1,+}{ }^{\text {, Jae Ho Jung }}{ }^{1}$, In Ho Song ${ }^{1}$, Hyun Soo Park ${ }^{1}$, Nunzio Denora ${ }^{3} \mathbb{D}^{\text {, }}$ \\ Francesco Leonetti $^{3}$ (D), Sang Eun Kim ${ }^{1,4,5, *}$ and Byung Chul Lee ${ }^{1,4, *(\mathbb{D})}$
}

1 Department of Nuclear Medicine, Seoul National University Bundang Hospital, Seoul National University College of Medicine, Seongnam 13620, Korea; kkpling@snu.ac.kr (S.H.L.); cjy0929@snu.ac.kr (J.Y.C.);

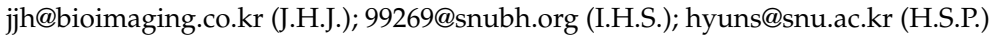

2 Department of Transdisciplinary Studies, Graduate School of Convergence Science and Technology, Seoul National University, Seoul 08826, Korea

3 Department of Pharmacy-Pharmaceutical Sciences, University of Bari “A. Moro”, 70121 Bari, Italy; nunzio.denora@uniba.it (N.D.); francesco.leonetti@uniba.it (F.L.)

4 Center for Nanomolecular Imaging and Innovative Drug Development, Advanced Institute of Convergence Technology, Suwon 16229, Korea

5 Department of Molecular Medicine and Biopharmaceutical Sciences, Graduate School of Convergence Science and Technology, Seoul National University, Seoul 08826, Korea

check for

updates

Citation: Lee, S.H.; Choi, J.Y.; Jung J.H.; Song, I.H.; Park, H.S.; Denora, N.; Leonetti, F.; Kim, S.E.; Lee, B.C. Effect of Peptide Receptor Radionuclide Therapy in

Combination with Temozolomide against Tumor Angiogenesis in a Glioblastoma Model. Cancers 2021, 13, 5029. https://doi.org/10.3390/ cancers13195029

Academic Editor: Hidehito Horinouchi

Received: 5 July 2021

Accepted: 4 October 2021

Published: 8 October 2021

Publisher's Note: MDPI stays neutral with regard to jurisdictional claims in published maps and institutional affiliations.

Copyright: () 2021 by the authors. Licensee MDPI, Basel, Switzerland. This article is an open access article distributed under the terms and conditions of the Creative Commons Attribution (CC BY) license (https:// creativecommons.org/licenses/by/ $4.0 /)$.
* $\quad$ Correspondence: kse@snu.ac.kr (S.E.K.); leebc@snu.ac.kr (B.C.L.); Tel.: +82-31-787-7671 (S.E.K.); +82-31-787-2956 (B.C.L.)

$+\quad$ Sang Hee Lee (S.H.L.) and Ji Young Choi (J.Y.C.) contributed equally to this study.

Simple Summary: Glioblastoma multiforme (GBM) is an aggressive brain tumor characterized by intense angiogenesis. Thus, tumor angiogenesis-related receptors, such as the cell adhesion molecule integrin $\alpha_{\mathrm{V}} \beta_{3}$, are potential biomarkers for cancer diagnosis and therapy. In this study, we aimed to investigate the therapeutic efficacy of peptide receptor radionuclide therapy (PRRT) with ${ }^{188}$ Re-IDAD- $\left[\mathrm{c}(\text { RGDfK) }]_{2}(11.1 \mathrm{MBq})\right.$. Our results revealed that PRRT combined with temozolomide markedly reduced the tumor volume compared with monotherapy. In summary, ${ }^{188}$ Re-IDA-D-[c(RGDfK) $]_{2}$ might be an effective radiotherapeutic agent for the treatment of GBM.

Abstract: Cell adhesion receptor integrin $\alpha_{v} \beta_{3}$ is a promising biomarker for developing tumorangiogenesis targeted theranostics. In this study, we aimed to examine the therapeutic potential of peptide receptor radionuclide therapy (PRRT) with ${ }^{188}$ Re-IDA-D-[c(RGDfK) $]_{2}(11.1 \mathrm{MBq})$. The results showed that the tumor volume was significantly decreased by $81 \%$ compared with the vehicletreated group in U87-MG xenografts. The quantitative in vivo anti-angiogenic responses of PRRT were obtained using ${ }^{99 \mathrm{~m}}$ Tc-IDA-D-[c(RGDfK) $]_{2}$ SPECT and corresponded to the measured tumor volume. PRRT combined with temozolomide (TMZ) resulted in a 93\% reduction in tumor volume, which was markedly greater than that of each agent used individually. In addition, histopathological characterization showed that PRRT combined with TMZ was superior to PRRT or TMZ alone, even when TMZ was used at half dose. Overall, our results indicated that integrin-targeted PRRT and TMZ combined therapy might be a new medical tool for the effective treatment of glioblastoma.

Keywords: tumor angiogenesis; temozolomide; combination therapy; peptide receptor radionuclide therapy

\section{Introduction}

Angiogenesis is essential for tumor growth and metastasis [1]. Tumor angiogenesisrelated receptors are promising biomarkers for cancer diagnosis and therapy [2]. The cell adhesion molecule integrin $\alpha_{\mathrm{v}} \beta_{3}$ is a specific marker of tumor angiogenesis and plays a crucial role in the advancement and metastatic spread of cancer [3]. Therefore, antagonists 
against integrin $\alpha_{v} \beta_{3}$ were designed and evaluated either for tumor-specific anticancer therapy or combined with various therapeutic anticancer agents [4]. In addition, integrin $\alpha_{v} \beta_{3}$ can be used to assess expression status in vivo noninvasively. Thus, it may be valuable for evaluating the efficacy of anti-integrin treatment in reducing tumor growth and spread in order to improve therapy planning and monitoring of anti-angiogenic therapies [5,6]. Tripeptide Arg-Gly-Asp (RGD) sequence has been proven effective as a specific binding motif for integrin receptors, and since, numerous radionuclide-labeled RGD peptides targeting integrin $\alpha_{v} \beta_{3}$ have been developed and used in positron emission tomography (PET) and single-photon emission computed tomography (SPECT), which can longitudinally diagnose tumor angiogenesis in cancer [7-17]. Theranostics combines diagnostic imaging and therapy into a single platform and is considered the next generation of personalized medicine [18]. Nuclear medicine imaging, along with radiotherapeutic agents, is effective in planning and monitoring biology-driven personalized radiotherapy. For instance, ${ }^{99 \mathrm{~m}} \mathrm{Tc} /{ }^{188} \mathrm{Re}$ is one of the most promising pairs owing to their favorable nuclear properties for diagnostic imaging $\left(\mathrm{t}_{1 / 2}=6 \mathrm{~h}\right.$, gamma energy of $\left.141 \mathrm{keV}\right)$ and tumor radiotherapy $\left(t_{1 / 2}=17 \mathrm{~h}\right.$, maximum beta energy of $\left.2.12 \mathrm{MeV}\right)$, respectively. Moreover, ${ }^{99 \mathrm{~m}} \mathrm{Tc}$ and ${ }^{188} \mathrm{Re}$ can be easily obtained by periodic aseptic elution of ${ }^{99} \mathrm{Mo} /{ }^{99 \mathrm{~m}} \mathrm{Tc}-$ and ${ }^{188} \mathrm{~W} /{ }^{188} \mathrm{Re}$-generator, respectively, and are thus suitable for routine clinical use.

Glioblastoma multiforme (GBM) is a highly vascularized cancer [19]. Glioma cells produce proangiogenic factors, including vascular endothelial growth factor (VEGF); additionally, high levels of these factors are correlated with high-grade malignancy and poor prognosis $[20,21]$. Temozolomide (TMZ), which is spontaneously cleaved in vivo and generates the reactive DNA alkylating agent monomethyl triazenoimidazole carboxamide that promotes apoptosis, is used as the current standard chemotherapeutic agent for newly diagnosed GBM. It is typically used for the treatment of GBM in conjunction with radiation therapy.

We have previously reported the development of ${ }^{99 m} \mathrm{Tc}$ - and ${ }^{188} \mathrm{Re}-$ labeled RGD dimer peptides ( ${ }^{99 \mathrm{~m}} \mathrm{Tc}$ - and ${ }^{188} \mathrm{Re}-\mathrm{IDA}-\mathrm{D}-[\mathrm{c}(\mathrm{RGDfK})]_{2}$ ), including the ${ }^{99 \mathrm{~m}} \mathrm{Tc}-$ or ${ }^{188} \mathrm{Re}(\mathrm{CO})_{3^{-}}$ (iminodiacetate, IDA) core for tumor angiogenesis imaging and radiotherapy [18]. Both radiolabeled RGD peptides have similar activity: i) very high integrin-binding affinity (0.4-0.5 nM) and ii) high tumor accumulation but relatively low liver and intestinal uptake. ${ }^{99 m}$ Tc-IDA-D-[c(RGDfK) $]_{2}$ SPECT not only showed remarkable integrin-targeting specificity, high sensitivity, and desirable excretion kinetics in tumor xenografts, but was also an efficacious and safe radiotracer for diagnosing integrin $\alpha_{v} \beta_{3}$-expressing tumors [22,23].

In this study, we evaluated the possible use of peptide receptor radionuclide therapy (PRRT) of ${ }^{188}$ Re-IDA-D-[c(RGDfK) $]_{2}$ with ${ }^{99 m}$ Tc-IDA-D-[c(RGDfK) $]_{2}$ as a promising theranostic strategy in U87-MG human glioblastoma xenografts. Furthermore, as the main aim of this study, we examine the possible synergistic effect of PRRT and TMZ and whether this combination is more effective than individual compounds.

\section{Materials and Methods}

\subsection{Chemicals}

Reagents and solvents were commercially purchased from Merck (Seoul, Korea) and used without further purification unless otherwise specified. The precursors (IDA-D$[\mathrm{c}(\mathrm{RGDfK})]_{2}$ and IDA-D-[c(RADfK) $\left.]_{2}\right)$ and three radiotracers ( ${ }^{99 \mathrm{~m}}$ Tc-IDA-D-[c(RGDfK) $]_{2}$, ${ }^{188}$ Re-IDA-D-[c(RGDfK) $]_{2}$, and ${ }^{188}$ Re-IDA-D-[c(RADfK $\left.\left.)\right]_{2}\right)$, and Q-dot 605-labeled RGD peptide (Q-dot 605-D-[c(RADfK) $]_{2}$ ) were prepared according to previously described methods [18,24]. The ${ }^{99} \mathrm{Mo} /{ }^{99} \mathrm{~m} \mathrm{Tc}-$ and ${ }^{188} \mathrm{~W} /{ }^{188} \mathrm{Re}$-generator was purchased from Samyoung Unitech (Seoul, Korea) and Enviro Korea (Daejeon, Korea), respectively.

\subsection{Cell Culture and Treatments}

The integrin $\alpha_{\mathrm{v}} \beta_{3}$ positive human glioblastoma cell, Uppsala87-Malignant Glioma (U87-MG, American Type Culture Collection (ATCC) ${ }^{\circledR}$ HTB-14 $^{\text {TM}}$; ATCC-LGC Standard, Wesel, Germany) was cultured in Dulbecco's Modified Eagle Medium (DMEM, Gibco, 
Grand Island, NY, USA) supplemented with 10\% fetal bovine serum (FBS) and 1\% antibiotics/antimycotics (Gibco, Grand Island, NY, USA) at $37^{\circ} \mathrm{C}$ in $5 \% \mathrm{CO}_{2}$.

\subsection{Preparation of Tumor-Bearing Mice}

A suspension of human glioblastoma U87-MG cells was prepared $\left(5 \times 10^{6}\right.$ cellsmL $\left.^{-1}\right)$. A total of $0.1 \mathrm{~mL}$ of cell suspension was injected subcutaneously into the right flank of a 6-7-week-old male BALB/c nu/nu nude mice (20-25 g, Orient Bio Inc., Seongnam, Korea). In the case of pharmacokinetic studies of ${ }^{99 \mathrm{~m}} \mathrm{Tc}-\mathrm{IDA}-\mathrm{D}-[\mathrm{c}(\mathrm{RGDfK})]_{2}$, we used tumor xenograft mice whose tumor cells were inoculated in the right shoulder and performed the SPECT imaging study when tumor volume reached $68.7 \pm 18.8 \mathrm{~mm}^{3}$ at 10 days after injection of U87-MG cells. Evaluations of integrin-targeted blocking and radiotherapy treatment on the growth of U87-MG xenografts were carried out when tumor volume reached $59.4 \pm 14.9 \mathrm{~mm}^{3}$ (For authentic "cold" Re-peptide ( ${ }^{185 / 187}$ Re-IDA-D-[c(RGDfK) $]_{2}$ ) treatment) and $66.2 \pm 15.3 \mathrm{~mm}^{3}$ (For radiotherapy $\left.\left({ }^{188} \text { Re-IDA-D-[c(RGDfK) }\right]_{2}\right)$ treatment) at 10 days after injection of U87-MG cells. Experiments with vehicle, negative control peptide $\left.\left({ }^{188} \text { Re-IDA-D-[c(RADfK) }\right]_{2}\right)$ or ${ }^{188}$ Re-IDA-D-[c(RGDfK) $]_{2}$ treatments $(11.1 \mathrm{MBq})$ in U87-MG xenografts were carried out when tumor volume reached $40.3 \pm 14.8 \mathrm{~mm}^{3}$ at 9 days after injection of U87-MG cells. The combination therapy of TMZ with ${ }^{188} \mathrm{Re}-$ IDA-D-[c(RGDfK) $]_{2}$, including single doses of TMZ, was carried out when tumor volume reached $47.9 \pm 8.6 \mathrm{~mm}^{3}$ at 9 days after injection of U87-MG cells. The body weight of mice for each group was maintained during all therapy experiments. All animal studies were performed under the protocols approved by the Institution Guidelines on the Use and Care of Animals. Mouse protocols were approved by Committee of Seoul National University Bundang Hospital (IACUC No. BA1211-117/080-01, approved on 27 November 2012). Animal Care and Use Committee. We performed the caliper measurements of the longest perpendicular tumor diameters.

\subsection{Radiotherapy for the U87-MG Xenografts}

All mice were intravenously injected with saline (Control group), "cold" 185/187 Recoordinated peptide $\left({ }^{185 / 187} \mathrm{Re}-\mathrm{IDA}-\mathrm{D}-[\mathrm{c}(\mathrm{RGDfK})]_{2}: \quad 0.013,5\right.$, and $\left.10 \mathrm{mgkg}^{-1}\right)$ or ${ }^{188} \mathrm{Re}-$ labeled peptide ( ${ }^{188}$ Re-IDA-D-[c(RGDfK) $]_{2}: 3.7,7.4,11.1$, and $\left.18.5 \mathrm{MBq}\right)$ every 4 days over a period of 14 days, and primary tumor growth was monitored daily for 2 weeks. Tumor volume was based on caliper or CT measurements. In cold, ${ }^{185 / 187}$ Re-IDA-D-[c(RGDfK) $]_{2}$ treatments, the dose of the ligand $\left(0.013 \mathrm{mgkg}^{-1}\right)$ was estimated from the molar activity of ${ }^{188}$ Re-IDA-D-[c(RGDfK) $]_{2}$ in an $18.5 \mathrm{MBq}$ radiotherapy dose.

\subsection{Combination Therapy of TMZ with ${ }^{188}$ Re-IDA-D-[c(RGDfK) $]_{2}$ in the U87-MG Xenografts}

U87-MG xenografts were assigned to various groups and injected intravenously for 2 weeks with planned treatments: saline (control), TMZ (2 or $\left.5 \mathrm{mgkg}^{-1}\right),{ }^{188} \mathrm{Re}-\mathrm{IDA}-\mathrm{D}-$ $[\mathrm{c}(\mathrm{RGDfK})]_{2}(11.1 \mathrm{MBq})$, or ${ }^{188}$ Re-IDA-D-[c(RGDfK) $]_{2}(11.1 \mathrm{MBq})+\mathrm{TMZ}\left(2 \mathrm{mgkg}^{-1}\right)$. TMZ was administered once a week for 14 days. ${ }^{188}$ Re-IDA-D-[c(RGDfK) $]_{2}$ was administered in 4 injections every 4 days over a period of 14 days. The experimental groups (4 mice for each) and corresponding control groups (4 mice) were examined. At the end of the experiment, animals were sacrificed, and tumors were excised and weighed.

\subsection{Immunohistochemistry}

Tumor tissues were harvested on day 14 after the treatment and immediately fixed in $10 \%$ formalin solution. Frozen tissue sections $(5 \mu \mathrm{m})$ were placed onto glass slides. The tumor sections were stained with anti-integrin $\alpha_{v} \beta_{3}$ rabbit antibody (1:1000, Millipore) at $4{ }^{\circ} \mathrm{C}$ for $16 \mathrm{~h}$. The sections were then incubated with anti-rabbit secondary antibody (biotinylated) at room temperature for $1 \mathrm{~h}$. The detection system (Vector Laboratories, Burlingame, CA, USA) was applied according to the manufacturer's instructions. The nuclei were counter-stained with hematoxylin (Invitrogen, Carlsbad, CA, USA). For assessment of tumor vascularization, mouse anti-human CD31 monoclonal antibody (diluted 
1:40, Dako) staining was performed on acetone-fixed cryosections using a blood vessel staining kit (ECM590, Millipore Ireland, Cork, Ireland). For another assessment of integrin $\alpha_{\mathrm{v}} \beta_{3}$ receptors in dissected tumor tissues, anti-integrin $\alpha_{\mathrm{v}} \beta_{3}$ (SC-7312, Santa Cruz Biotech, Santa Cruz, CA, USA) was used. Primary antibody against $\gamma \mathrm{H} 2 \mathrm{AX}$ (diluted 1:50, Abcam) was applied to acetone-fixed cryosections and incubated overnight. Secondary donkey anti-goat antibody (FITC conjugated, Invitrogen, Carlsbad, CA, USA) was applied and incubated for $1 \mathrm{~h}$. Immunohistochemical staining was performed at 30 days after excision of tumor due to the half-life of radioisotope (Re-188). Images were acquired using Axioscope A1 fluorescent microscope (Carl Zeiss, Jena, Germany) or AxioCam MRc5 (Carl Zeiss, Jena, Germany) and analyzed with Axiovision software (version 4.4, Carl Zeiss Meditec, Jena, Germany). The nuclei were counter-stained with hematoxylin (Invitrogen, Carlsbad, CA, USA).

\subsection{Confocal Microscopy}

Fluorescence images of Q-dot 605-D-[c(RGDfK) $]_{2}$ were collected using a Zeiss LSM510 META Confocal Imaging System with a Chameleon laser system (Carl Zeiss, Jena, Germany). All images were taken with an EC-Plan Neo-Fluar $40 \times$ (NA 1.3) oil immersion lens. The Q-dot 605 was excited at $543 \mathrm{~nm}$, and emission was monitored from 590 to $620 \mathrm{~nm}$. Images were analyzed using Zeiss LSM software (Carl Zeiss, Jena, Germany).

\subsection{Tumor Growth Measurement}

For caliper measurements, tumor length (longitudinal diameter) and tumor width (transverse diameter) were measured, and the tumor volume was calculated according to the following formula: tumor volume $=\left(\right.$ length $\times$ width $\left.^{2}\right) / 2$.

Animal CT imaging was performed using NanoSPECT/CT (Bioscan Inc., Washington, $\mathrm{DC}$, USA) consisting of a low-energy $\mathrm{X}$-ray tube and a precision-motion translation stage. A total of 180 projections were acquired with the X-ray source set at $45 \mathrm{kVp}$ and $177 \mathrm{~mA}$. Two-dimensional slices were reconstructed using an Exact Cone Beam Filter Back Projection algorithm with a Shepp-Logan filter. CT images were reconstructed on a voxel/pixel size of 0.20:0.192 mm, providing image sizes $(x, y, z)$ of $176 \times 176 \times 136$ with an image resolution of $48 \mathrm{~mm}$.

\subsection{SPECT Image Analysis}

Animal SPECT/CT imaging was acquired using a NanoSPECT/CT using low-energy and high-resolution pyramid collimator. Mice were placed in a prone position on the bed and kept under anesthesia with $2 \%$ isoflurane. SPECT images were obtained at 0 to $180 \mathrm{~min}$ after intravenous injection of ${ }^{99 \mathrm{~m}} \mathrm{Tc}-\mathrm{IDA}-\mathrm{D}-[\mathrm{c}(\mathrm{RGDfK})]_{2}(18.5 \mathrm{MBq}, n=4)$. After SPECT imaging, whole-body CT images were obtained in 24 projections over a $10 \mathrm{~min}$ period using a 4-head scanner with $4 \times 9(1.4 \mathrm{~mm})$ pinhole collimators in helical scanning mode. Image reconstruction and quantification of micro-SPECT and CT images was performed using the software programs HiSPECT (version 1.0, Bioscan Inc. Washington, DC, USA) and InVivoScope software (version 1.43, Bioscan Inc. Washington, DC, USA), respectively. The percentage of the injected dose per gram of tissue $\left(\% \mathrm{IDg}^{-1}\right)$ was determined from the radionuclide uptake in the region of interest (ROI) on the tumor after intravenous injection of ${ }^{99 \mathrm{~m}} \mathrm{Tc}-\mathrm{IDA}-\mathrm{D}-[\mathrm{c}(\mathrm{RGDfK})]_{2}$.

\subsection{Statistical Analysis}

Statistical software SPSS version 10.1 (SPSS Inc., Chicago, IL, USA) was used for analyzing results. Multiple group comparisons were made using one-way ANOVA followed by post hoc test (Bonferroni correction). Differences with a $p$-value less than 0.05 were considered as significant. 


\section{Results}

\subsection{Pharmacokinetic Studies of ${ }^{99 m} T c-I D A-D-[c(R G D f K)]_{2}$ in U87-MG Xenografts}

As shown in Figure $1 \mathrm{~A},{ }^{99 \mathrm{~m}} \mathrm{Tc}-\mathrm{IDA}-\mathrm{D}-[\mathrm{c}(\mathrm{RGDfK})]_{2}$ had prominent tumor accumulation and retention potential with rapid general clearance mainly through the kidneys and to a lesser extent through the liver. The quantified tumor uptake of ${ }^{99 \mathrm{~m}} \mathrm{Tc}-\mathrm{IDA}-\mathrm{D}-[\mathrm{c}(\mathrm{RGDfK})]_{2}$ was measured from the ROI of SPECT images and expressed as a percentage of the injected dose per gram tissue $\left(\% \mathrm{IDg}^{-1}\right)$ (Figure $\left.1 \mathrm{~B}\right)$.

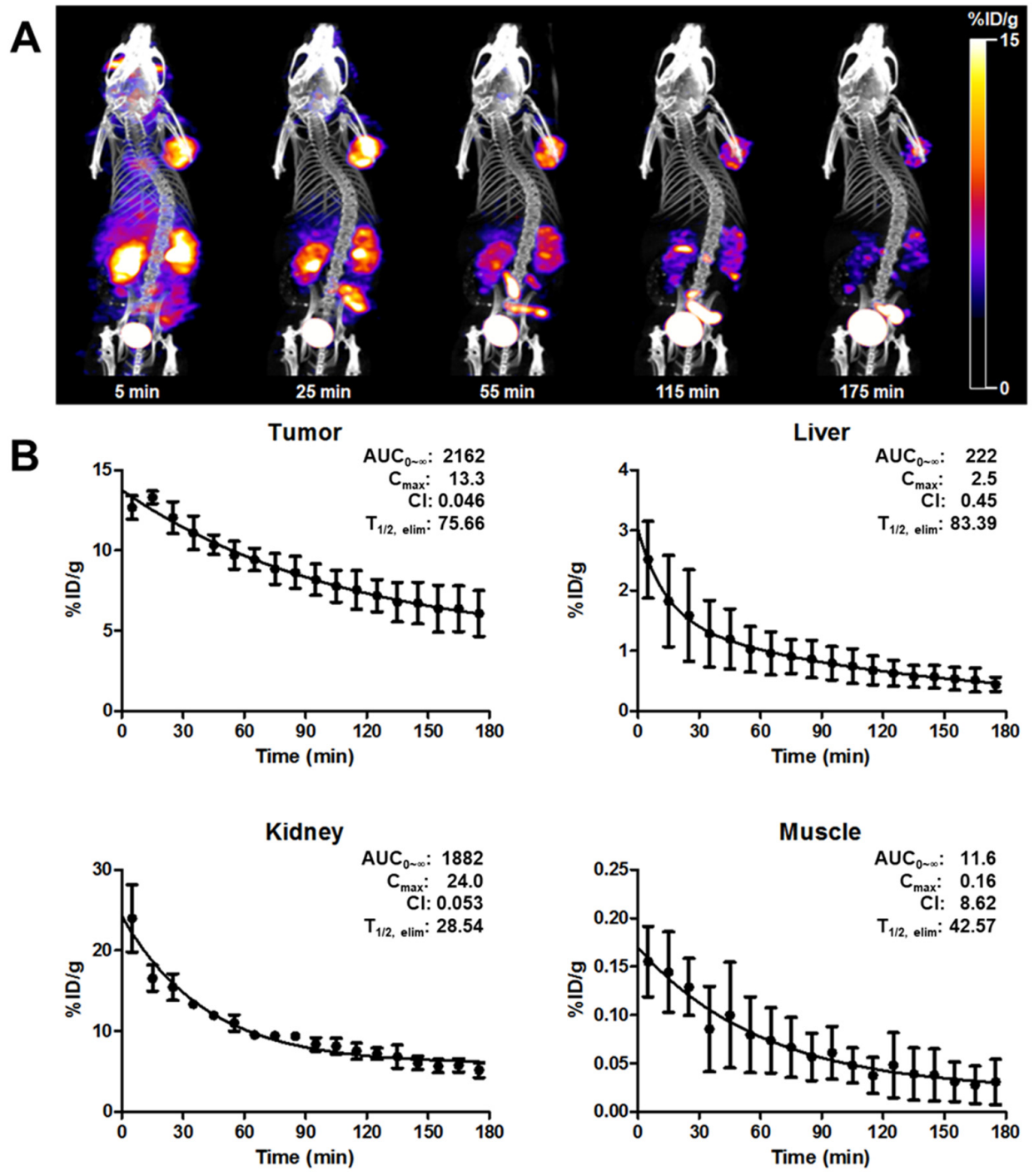

Figure 1. In vivo characteristics of ${ }^{99 \mathrm{~m}} \mathrm{Tc}-\mathrm{IDA}-\mathrm{D}-[\mathrm{c}(\mathrm{RGDfK})]_{2}$. Representative serial SPECT/CT images of ${ }^{99 m}$ Tc-IDA-D-[c(RGDfK) $]_{2}$ in the U87-MG xenograft (A). ROI-derived radionuclide uptake of tumor, liver, kidneys, and muscle post-injection of ${ }^{99 m}$ Tc-IDA-D-[c(RGDfK) $]_{2}$ (B). Color bars indicate the range of radionuclide uptake as $\% \mathrm{IDg}^{-1}$. Results are given as the means $\pm \mathrm{SD}(n=3)$. $\mathrm{AUC}_{0-\infty}$ : the area under the concentration-time curve $\left(\% \mathrm{IDg}^{-1} \cdot \mathrm{min}\right), \mathrm{C}_{\max }$ : the maximum concentrations $\left(\% \mathrm{IDg}^{-1}\right), \mathrm{Cl}$ : the clearance rate $\left(\mathrm{mLmin}^{-1}\right) ; \mathrm{T}_{1 / 2}$ elim t the elimination half-life (min).

The noninvasive measurement of tumor size and radionuclide uptake using ${ }^{99 \mathrm{~m}} \mathrm{Tc}-$ IDA-D-[c(RGDfK) $]_{2}$ SPECT was compared with conventional measurements of caliper and gamma counter, respectively. Our analysis revealed a positive correlation between in vivo animal SPECT/CT semi-quantification image analysis and ex vivo tumor radionuclide uptake measurements $\left(\mathrm{R}^{2}=0.894\right.$; Supplementary Figure S1). Thus, ROI-derived $\% \mathrm{IDg}^{-1}$ 
values provided high-confidence values for assessing the angiogenic response in tumorbearing mice $(n=13)$ with tumor volumes of $64.2-3569.4 \mathrm{~mm}^{3}$.

To anticipate the therapeutic efficacy and side effects of ${ }^{188}$ Re-IDA-D-[c(RGDfK) $]_{2}$, we assessed the pharmacokinetic (PK) parameters of ${ }^{99 \mathrm{~m}} \mathrm{Tc}-\mathrm{IDA}-\mathrm{D}-[\mathrm{c}(\mathrm{RGDfK})]_{2}$ in three tumorbearing nude mice. PK parameters were derived using nonlinear regression curve fitting. The area under the curve $\left(\mathrm{AUC}_{0-\infty}\right)$ that was obtained by plotting concentration versus time for ${ }^{99 \mathrm{~m}}$ Tc-IDA-D-[c(RGDfK) $]_{2}$ in the liver and muscle was proportionally 10- and 200-fold lower than that in the tumor, respectively. The $\mathrm{AUC}_{0}-\infty$ of tumor was slightly higher than that of the kidneys. The maximum concentrations $\left(\mathrm{C}_{\max }\right)$ of ${ }^{99 \mathrm{~m}} \mathrm{Tc}-\mathrm{IDA}-\mathrm{D}-[\mathrm{c}(\mathrm{RGDfK})]_{2}$ in the tumor and kidneys were 13.3 and $24.0 \% \mathrm{IDg}^{-1}$, respectively.

The elimination half-life $\left(\mathrm{T}_{1 / 2}\right.$ elim $)$ of ${ }^{99 \mathrm{~m}} \mathrm{Tc}-\mathrm{IDA}-\mathrm{D}-[\mathrm{c}(\mathrm{RGDfK})]_{2}$ in the liver was $83.39 \mathrm{~min}$, which was 1.10 -fold higher than that in the tumor. The clearance rate $(\mathrm{Cl})$ and $\mathrm{T}_{1 / 2}$ elim of ${ }^{99 \mathrm{~m}} \mathrm{Tc}-\mathrm{IDA}-\mathrm{D}-\left[\mathrm{c}(\text { RGDfK) }]_{2}\right.$ in the kidneys were $0.053 \mathrm{mLmin}^{-1}$ and $28.54 \mathrm{~min}$, respectively. These results partially showed that the kidneys eliminated the radionuclide uptake more rapidly than the tumor. However, these PK parameters from SPECT imaging indicated that the repeated dosing and renal toxicity of ${ }^{188}$ Re-IDA-D-[c(RGDfK) $]_{2}$ need to be considered before pharmacological evaluation.

\subsection{Anti-Angiogenic Effect of ${ }^{188} R e-I D A-D-[c(R G D f K)]_{2}$}

For a preliminary study (Supplementary Figure S2), a single dose (22.2 MBq in $200 \mu \mathrm{L}$ of saline) of ${ }^{188}$ Re-IDA-D-[c(RGDfK) $]_{2}$ and only saline $(200 \mu \mathrm{L})$ were injected into U87MG xenografts (tumor volume $=300 \mathrm{~mm}^{3}$ ). At $3 \mathrm{~d}$ post-injection, the tumor volumes of ${ }^{188}$ Re-IDA-D-[c(RGDfK) $]_{2}$-treated mice slightly increased to $350 \mathrm{~mm}^{3}$, whereas those of saline-treated mice more than doubled. In addition, the observed $\% \mathrm{IDg}^{-1}$ of ${ }^{99 \mathrm{~m}} \mathrm{Tc}-\mathrm{IDA}$ D-[c(RGDfK) $]_{2}$ (approximately $10 \% \mathrm{IDg}^{-1}$ ) of a tumor before ${ }^{188} \operatorname{Re}-\mathrm{IDA}-\mathrm{D}-[\mathrm{c}(\mathrm{RGDfK})]_{2}$ injection significantly reduced by 50\%. CD31 immunostaining for microvessels, and fluorescence imaging of Q-dot 605-D-[c(RGDfK) $]_{2}$ for integrin receptors also revealed the anti-angiogenic efficacy of ${ }^{188}$ Re-IDA-D-[c(RGDfK) $]_{2}$ on the tumor tissue. The antiangiogenic effect of integrin-targeted therapy is probably brief since rapid revascularization of tumors occurs after discontinuing anti-VEGF treatment $[25,26]$. Therefore, injection of ${ }^{188} \mathrm{Re}$-IDA-D-[c(RGDfK) $]_{2}$ was performed every $4 \mathrm{~d}$ throughout $14 \mathrm{~d}$ based on the preliminary PK parameters of ${ }^{99 \mathrm{~m}} \mathrm{Tc}-\mathrm{IDA}-\mathrm{D}-[\mathrm{c}(\mathrm{RGDfK})]_{2}$ and the periodic elution time of the ${ }^{188} \mathrm{~W} /{ }^{188}$ Re-generator.

Before radiotherapy, U87-MG xenografts were treated with saline (control) and ${ }^{185 / 187}$ Re-coordinated IDA-D-[c(RGDfK) $]_{2}\left(0.013-10 \mathrm{mgkg}^{-1}\right.$ in saline) to clarify whether the cold Re-peptide also has an anti-angiogenic effect as the integrin antagonist (Figure 2A). The results indicated that the amount $\left(0.013 \mathrm{mgkg}^{-1}\right)$ of ${ }^{185 / 187} \mathrm{Re}$-coordinated IDA-D$[c(\text { RGDfK })]_{2}$, which was calculated from the molar activity of ${ }^{188}$ Re-IDA-D-[c(RGDfK) $]_{2}$, had no pharmacodynamic effect in the tumor model. Furthermore, when tumors were treated with cold Re-peptide ( $\left.{ }^{185 / 187} \operatorname{Re}-I D A-D-[c(R G D f K)]_{2}\right)$, the inhibitions of tumor growth showed a linear relationship with doses. Although treatments with ${ }^{185} / 187$ Re-IDAD- $[\mathrm{c}(\text { RGDfK })]_{2}$ had a minimal impact on tumors, the PRRT of ${ }^{188}$ Re-IDA-D-[c(RGDfK) $]_{2}$ markedly affected tumor growth (Figure 2C). After $14 \mathrm{~d}$ of treatment, ${ }^{188}$ Re-IDA-D$[\mathrm{c}(\mathrm{RGDfK})]_{2}$ at low doses of 3.7 and $7.4 \mathrm{MBq}$ could significantly suppress tumor growth by $33 \%$ and $56 \%(p<0.05)$, respectively, compared with the control group. In contrast, at higher doses of 11.1 and $18.5 \mathrm{MBq}$, it could completely inhibit tumor growth (64\% and $69 \%$ in tumor size reduction, respectively, compared with the control). Overall, ${ }^{188}$ Re-IDA-D$[\mathrm{c}(\mathrm{RGDfK})]_{2}$ treatments showed good tolerance in all experiments and did not result in body weight changes, except for the $18.5 \mathrm{MBq}$ dose. 
A
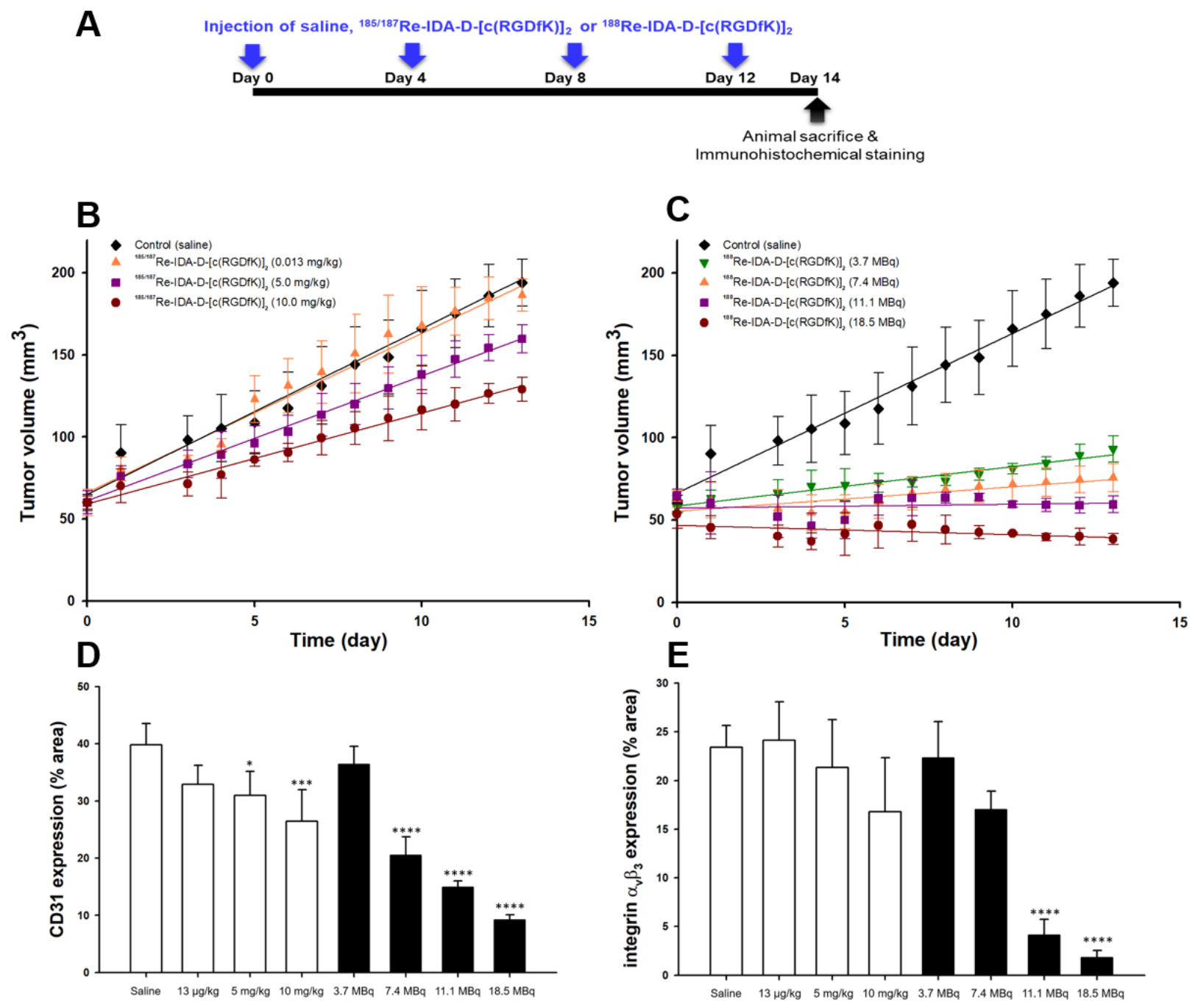

Figure 2. Effects of integrin targeted blocking and radiotherapy on the growth of U87-MG xenografts. (A) Schematic protocol of the treatment. (B) The authentic "cold" Re-peptide (185/187 Re-IDA-D-[c(RGDfK) $\left.]_{2}\right)$ dose response for tumor volume. (C) Radiotherapy $\left({ }^{188}\right.$ Re-IDA-D- $\left.[\mathrm{c}(\mathrm{RGDfK})]_{2}\right)$ dose response for tumor volume. Four mice were used for each time point. (D) Microvessel and (E) integrin $\alpha_{\mathrm{v}} \beta_{3}$ positive $\%$ area of tumors treated with either saline, ${ }^{185 / 187}$ Re-IDA-D-[c(RGDfK) $]_{2}$ $\left(0.013,5\right.$, and $\left.10 \mathrm{mgkg}^{-1}\right)$, or ${ }^{188}$ Re-IDA-D-[c(RGDfK) $]_{2}(3.7,7.4,11.1$, and $18.5 \mathrm{MBq})$ after 2 weeks. Expression levels of microvessel and integrin $\alpha_{\mathrm{v}} \beta_{3}$ were evaluated in all tested experimental groups. Error bars represent means \pm SD. Data were analyzed by ANOVA test and post hoc test (each group versus control group, ${ }^{*} p<0.05,{ }^{* * *} p<0.001,{ }^{* * * *} p<0.0001$ ).

Immunohistochemical analysis of the dissected tumor tissues with the anti-human CD31 monoclonal antibody and anti-integrin $\alpha_{\mathrm{v}} \beta_{3}$ antibody showed reduced microvessel density and anti-angiogenic effects in tumor tissues (Figure 2D,E). These results indicated that integrin-targeted PRRT was superior to integrin-targeted treatment inhibition. CD31 immunostaining data supported the significant anti-angiogenic effect of ${ }^{188}$ Re-IDAD- $[\mathrm{c}(\mathrm{RGDfK})]_{2}$ with increasing radiotherapy doses [27]. The \% area of CD31 positive microvessels was decreased to $31 \%$ at $5 \mathrm{mgkg}^{-1}$ and $26 \%$ at $10 \mathrm{mgkg}^{-1}$ in the ${ }^{185 / 187} \mathrm{Re}^{-}$ IDA-D-[c(RGDfK) $]_{2}$-treated group. In contrast, the ${ }^{188}$ Re-IDA-D-[c(RGDfK) $]_{2}$-treated group showed markedly increased destruction of tumor tissue microvessels in a linear radioactivity dose-dependent manner. Moreover, immunohistochemical staining with anti-integrin $\alpha_{v} \beta_{3}$ antibody revealed the suppression of tumor growth in groups treated with 11.1 and 18.5 MBq ${ }^{188}$ Re-IDA-D-[c(RGDfK) $]_{2}$ accompanied by an $82 \%$ and $92 \%$ decrease in integrin expression levels, respectively, compared with the control. 


\subsection{Selectivity of Radiotherapy}

After determining the optimal effective radiotherapeutic dose at $11.1 \mathrm{MBq}$, we investigated whether ${ }^{188}$ Re-IDA-D-[c(RGDfK) $]_{2}$ has a selective anti-angiogenic effect on U87-MG tumors compared with the negative control peptide ${ }^{188}$ Re-IDA-D-[c(RADfK $\left.)\right]_{2}$, which does not bind integrin $\alpha_{\mathrm{v}} \beta_{3}$ owing to the addition of a single methyl group, changing glycine to alanine $[28,29]$. We analyzed the ability of ${ }^{188}$ Re-IDA-D-[c(RGDfK) $]_{2}$ in suppressing tumor growth in U87-MG xenografts after $14 \mathrm{~d}$ of treatment, and the results were compared with those of "vehicle" $\left(0.013 \mathrm{mgkg}^{-1} \text { of }{ }^{185 / 187} \text { Re-IDA-D-[c(RGDfK) }\right]_{2}$ in saline) and negative control peptide-treated groups (Figure 3). No suppression of tumor growth was observed in mice xenografts when treated with $11.1 \mathrm{MBq}$ of negative control peptide. In contrast, we observed $81 \%$ tumor volume reduction in the ${ }^{188}$ Re-IDA-D-[c(RGDfK) $]_{2}$-treated group compared with the vehicle-treated group.

A

Injection of vehicle, Negative control peptide or ${ }^{188}$ Re-IDA-D-[C(RGDfK)]

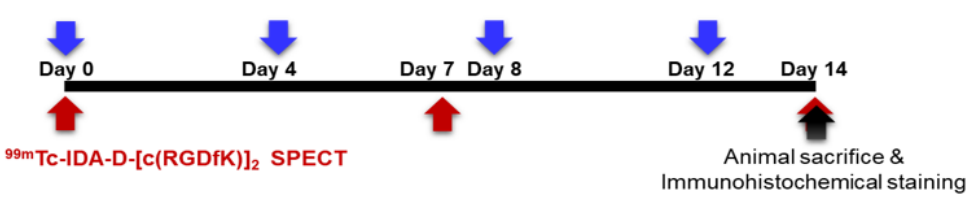

B

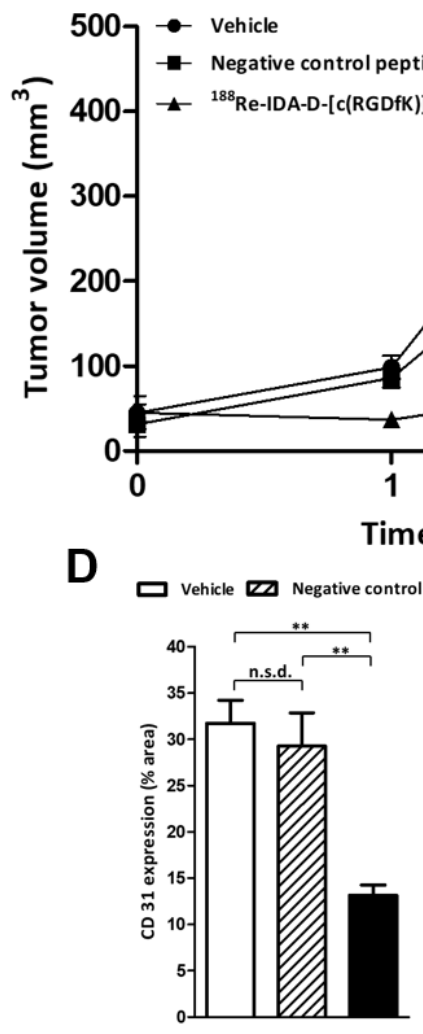

C Immunohistochemical staining

\section{C}
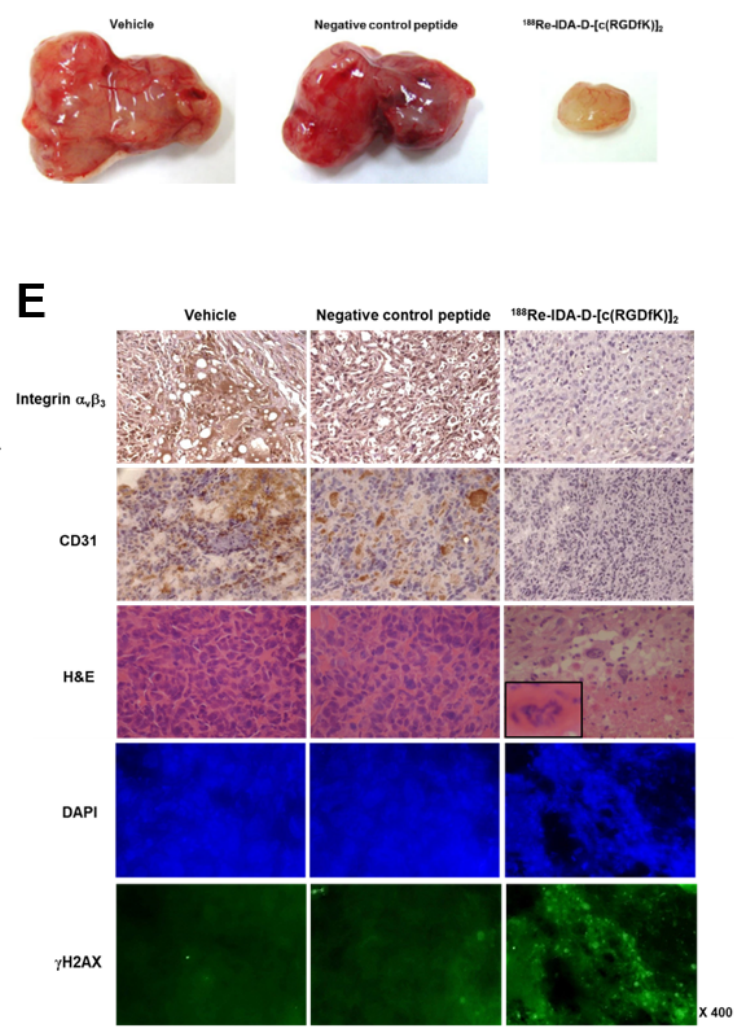

Figure 3. Anti-angiogenic effects of ${ }^{188}$ Re-IDA-D-[c(RGDfK) $]_{2}(11.1 \mathrm{MBq})$ in U87-MG xenografts. Tumor-bearing mice were treated with either vehicle, negative control peptide $\left.\left({ }^{188} \text { Re-IDA-D-[c(RADfK) }\right]_{2}\right)$, or ${ }^{188} \operatorname{Re}-I D A-D-[c(R G D f K)]_{2}$ for 2 weeks ( $n=4$ for each). (A) Schematic protocol of the treatment. (B) Tumor volume at each time point. (C) Representative macroscopic appearance of the dissected tumors in three groups. (D) Microvessel and integrin $\alpha_{\mathrm{v}} \beta_{3}$ positive \% area of tumors treated in all tested experimental groups after 2 weeks. (E) Immunohistochemical staining with anti- $\alpha_{\mathrm{v}} \beta_{3}$, anti-CD31, and H\&E and immunofluorescence images with DAPI and $\gamma \mathrm{H} 2 \mathrm{AX}$ for DNA damage in the tumor sections. Data were analyzed by ANOVA test and post hoc test (Bonferroni correction, ${ }^{* *} p<0.01,{ }^{* * *} p<0.001,{ }^{* * * *} p<0.0001$ ). Abbreviation: NSD means no significant difference. 
Based on macroscopic observations, the dissected tumors in the ${ }^{188}$ Re-IDA-D-[c(RGDfK) $]_{2}$ treated group appeared less vascularized than those in the vehicle- and negative control peptide-treated groups (Figure 3C). Histological examination also revealed significant differences among the groups. The ${ }^{188} \mathrm{Re}-\mathrm{IDA}-\mathrm{D}-[\mathrm{c}(\mathrm{RGDfK})]_{2}$-treated tumor tissues showed a decrease in microvessel density of approximately $60 \%$ as assessed by CD31 immunostaining (Figure 3D) and a significant decrease in positive integrin $\alpha_{\mathrm{v}} \beta_{3}$ staining. Therefore, the anti-angiogenic effects of ${ }^{188}$ Re-IDA-D-[c(RGDfK) $]_{2}$ might be partly responsible for the delay in tumor growth. We also found that beta radiation from ${ }^{188}$ Re-IDA-D-[c(RGDfK) $]_{2}$ damaged cancer cells in the tumor angiogenic region and reduced the concentration of integrin $\alpha_{\mathrm{v}} \beta_{3}$ receptors. In the nuclei of tumor tissues counter-stained with hematoxylin, ${ }^{188}$ Re-IDA-D-[c(RGDfK) $]_{2}$-treated tumor tissues showed a damaged architecture and less intense staining, leading to massive necrosis. Radiotherapy-induced tumor necrosis was evident in the lower half of the field, whereas several scattered large tumor cells with generative features were observed in the upper half of the field (Figure 3E). The inset picture of ${ }^{188}$ Re-IDA-D-[c(RGDFK) $]_{2}$-treated tumor tissue revealed radiation-induced damages of tumor vessels, endothelial cell swelling, and fibrinoid changes in the wall. The necrotizing effect was associated with the prolongation of $\gamma \mathrm{H} 2 \mathrm{AX}$ foci following irradiation with beta rays from ${ }^{188} \mathrm{Re}-\mathrm{IDA}-\mathrm{D}-[\mathrm{c}(\mathrm{RGDfK})]_{2}$ (Figure 3E) [30]. To confirm the anti-angiogenic effect in the ${ }^{188} \mathrm{Re}-\mathrm{IDA}-\mathrm{D}-[\mathrm{c}(\mathrm{RGDfK})]_{2}$-treated group, we prepared Q-dot 605-labeled RGD peptide for ex vivo scanning in cryosections (Supplementary Figure S3), and we obtained sufficient evidence of damages in integrin $\alpha_{v} \beta_{3}$ after treatment with ${ }^{188}$ Re-IDA-D-[c(RGDfK) $]_{2}$.

\subsection{Theranostics for Tumor Angiogenesis}

As an integrin-targeted theranostic strategy, ${ }^{99 \mathrm{~m}} \mathrm{Tc}-\mathrm{IDA}-\mathrm{D}-[\mathrm{c}(\mathrm{RGDfK})]_{2}$ SPECT was performed in all tested experimental groups (Figure 3) to assess the extent of damage in integrin receptor due to noninvasive beta irradiation of PRRT (Figure 4). Changes in the radionuclide uptake of ${ }^{99 \mathrm{~m}} \mathrm{Tc}-\mathrm{IDA}-\mathrm{D}-[\mathrm{c}(\mathrm{RGDfK})]_{2}$ in the tumor region were measured every $7 \mathrm{~d}$. Vehicle- and negative control peptide-treated groups showed a rapid increase in the integrin-mediated uptake levels at $7 \mathrm{~d}$ of treatment $(13.5 \pm 1.8$ and $13.1 \pm 1.5 \%$ $\mathrm{IDg}^{-1}$, respectively) and then a slight decrease at $14 \mathrm{~d}$ of treatment owing to the rapid enlargement of tumor size. In contrast, SPECT/CT analysis revealed that treatment with ${ }^{188}$ Re-IDA-D-[c(RGDfK) $]_{2}$ significantly suppressed integrin $\alpha_{\mathrm{v}} \beta_{3}$ expression and reduced tumor growth in vivo. The tumor volume of the ${ }^{188}$ Re-IDA-D-[c(RGDfK) $]_{2}$-treated group at $14 \mathrm{~d}$ of treatment was similar to that of the vehicle-treated group at $7 \mathrm{~d}$ of treatment (Figure 4A); however, the percentage $\mathrm{IDg}^{-1}$ in the tumor region displayed differences between the two groups (13.5 \pm 1.8 and $9.02 \pm 0.6 \% \mathrm{IDg}^{-1}$, respectively; $p<0.05$ ).

\subsection{PRRT Combined with TMZ}

To evaluate the combined antitumoral activity of internal radiation and chemotherapy in gliomas, we selected the anticancer drug TMZ (Figure 5), which represents the standard therapy for glioblastoma, although its dose-dependent side effects often limit its use.

TMZ treatment significantly reduced tumor size compared with saline treatment but without any significant dose-dependent differences. Although no dose-dependent responses were observed until day 14 of treatment, histological results showed that high doses of TMZ ( $5 \mathrm{mgkg}^{-1}$ ) reduced integrin expression in tumor tissues (Figure 5C,D). The combined use of ${ }^{188}$ Re-IDA-D-[c(RGDfK) $]_{2}$ and TMZ $\left(2 \mathrm{mgkg}^{-1}\right)$ resulted in the best anti-tumor results as confirmed by histological examination that demonstrated a significant reduction in microvessel density (97.9\% reduction of positive \% area for CD31 expression) and integrin receptors (98.5\% reduction of positive \% area for integrin $\alpha_{\mathrm{v}} \beta_{3}$ expression) (Figure 5C). These results revealed that combined therapy with ${ }^{188}$ Re-IDA-D-[c(RGDfK) $]_{2}$ and TMZ could deplete the angiogenic process and retard glioblastoma progression. 
A

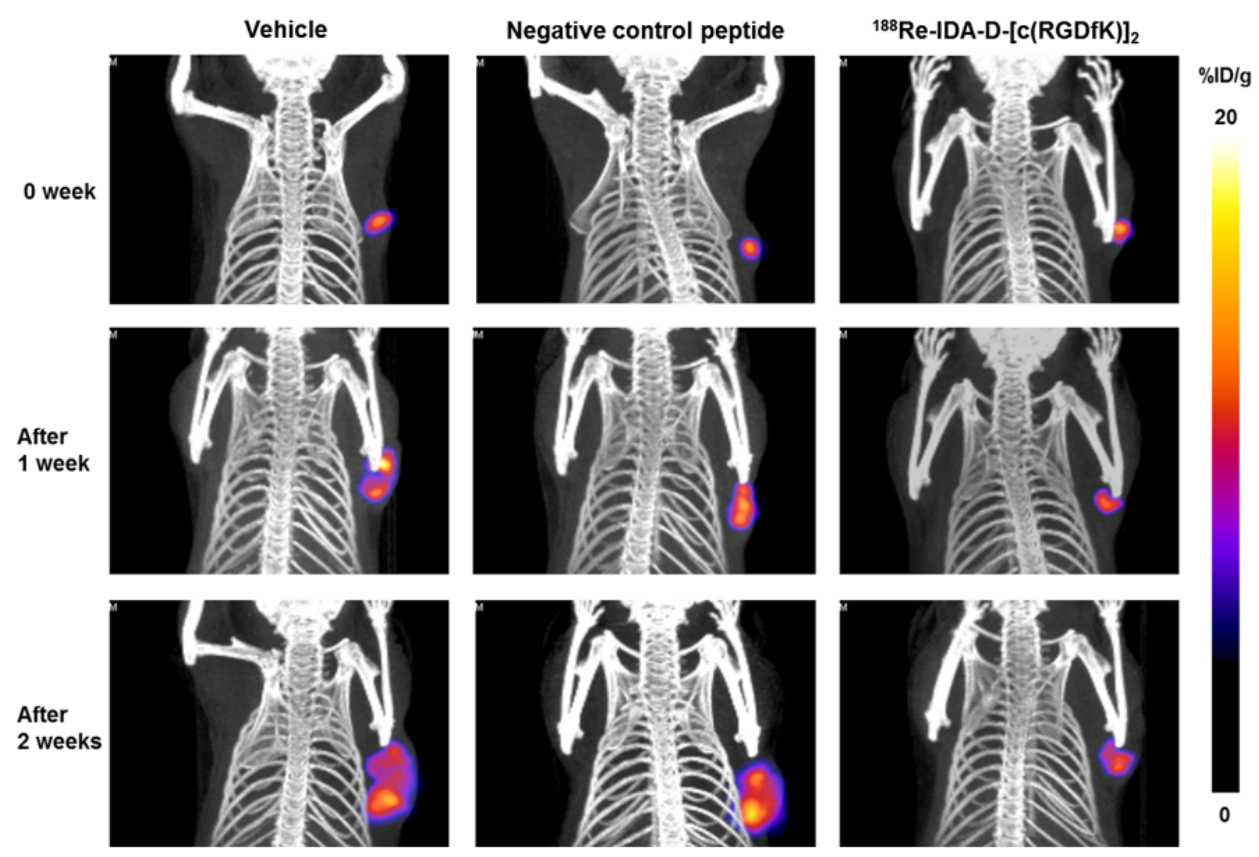

B

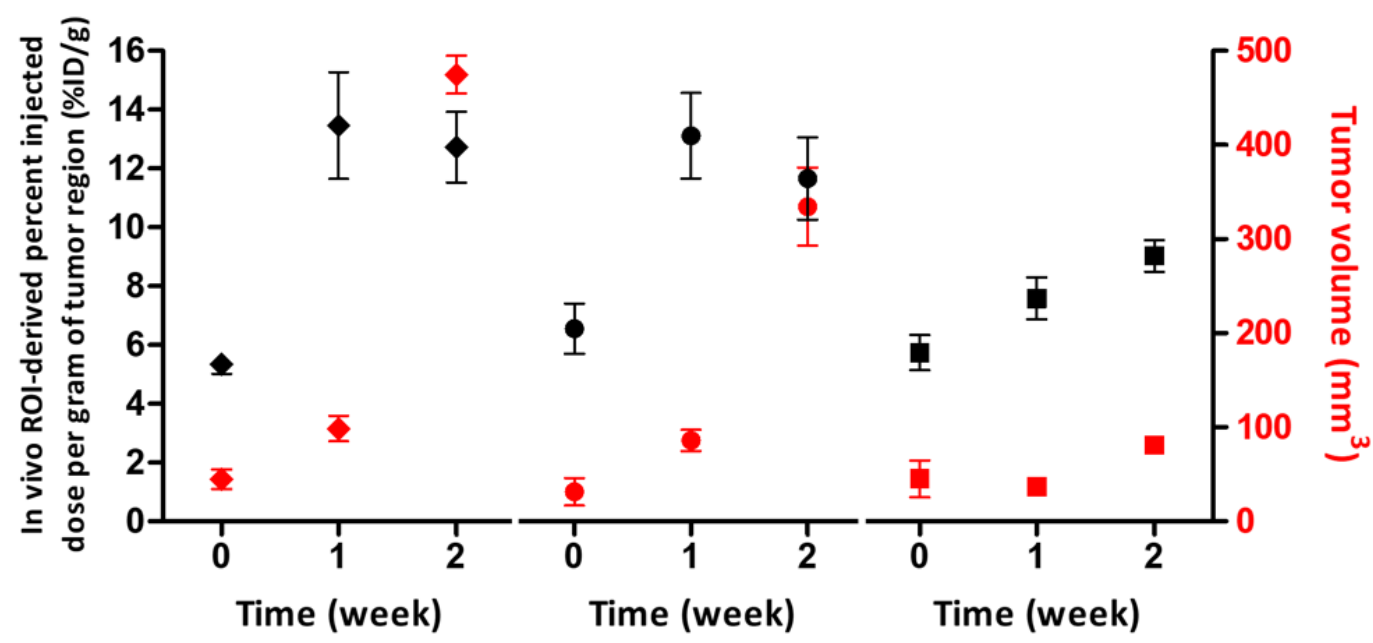

Figure 4. Differences in the uptake of ${ }^{99} \mathrm{~m}$ Tc-IDA-D- $[\mathrm{c}(\mathrm{RGDfK})]_{2}$ in images in grouped mice as $\% \mathrm{IDg}^{-1}$ indicate considerable anti-angiogenic response. (A) ${ }^{99}$ Tc-IDA-D-[c(RGDfK) $]_{2}$ SPECT imaging of integrin $\alpha_{\mathrm{v}} \beta_{3}$ in the U87-MG xenografts before and after administration of the vehicle (closed lozenge), negative control peptide ( ${ }^{188}$ Re-IDA-D-[c(RADfK) $]_{2}$, closed circle) or ${ }^{188}$ Re-IDA-D-[c(RGDfK) $]_{2}$ (closed square) treatment. (B) Measurement of $\% \mathrm{IDg}^{-1}$ of ${ }^{99 \mathrm{~m}} \mathrm{Tc}-\mathrm{IDA}-\mathrm{D}-[\mathrm{c}(\mathrm{RGDfK})]_{2}$ in the tumor region (black color, left y-axis) and tumor volume at each time (red color, right y-axis) from mice treated with vehicle, negative control peptide or ${ }^{188}$ Re-IDA-D-[c(RGDfK) $]_{2}$. 


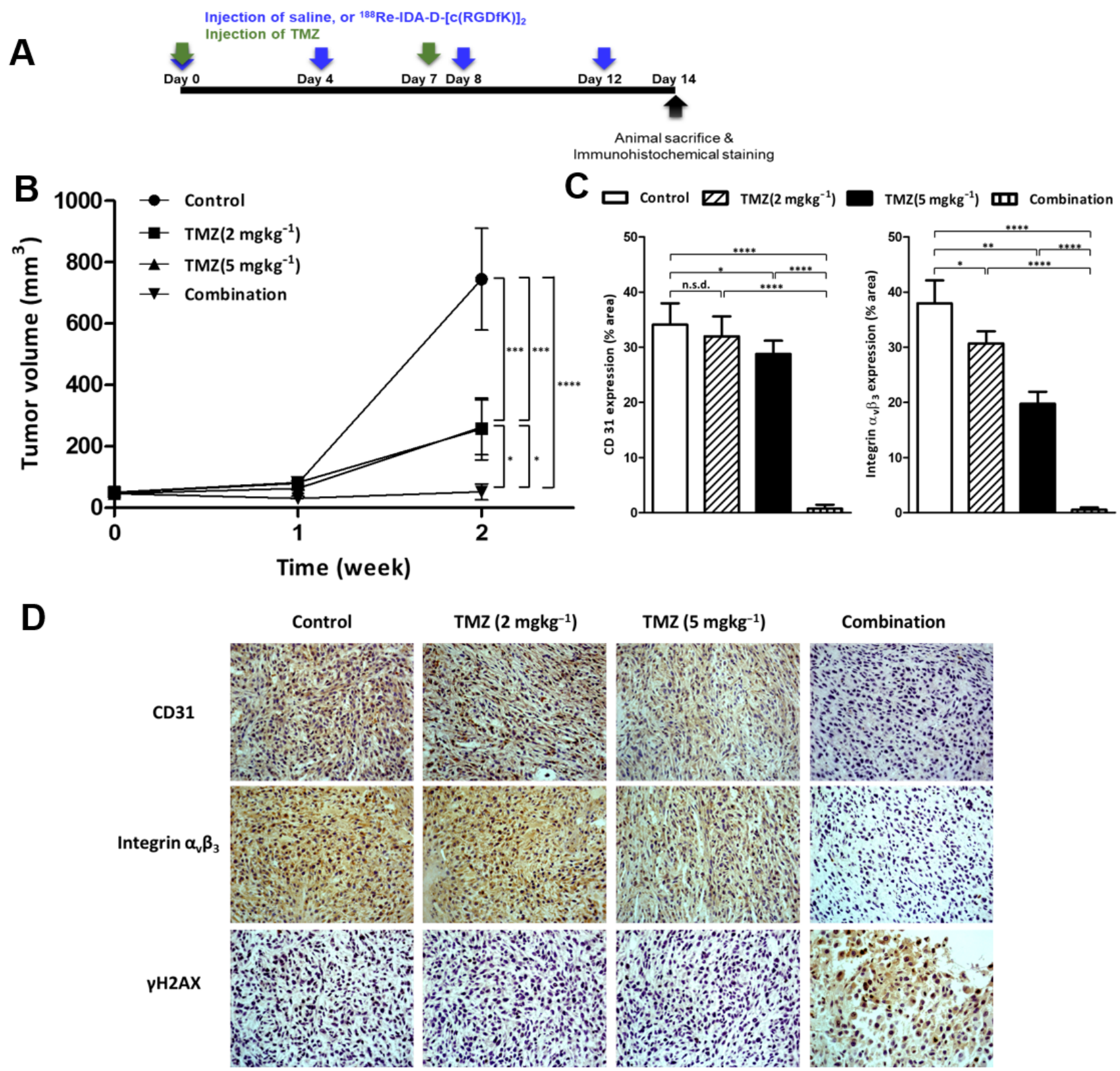

Figure 5. Therapeutic effect of ${ }^{188}$ Re-IDA-D-[c(RGDfK) $]_{2}$ combined with TMZ in the U87-MG xenografts. Tumor-bearing mice were treated with either control (saline), TMZ $\left(2\right.$ or $\left.5 \mathrm{mgkg}^{-1}\right)$, or a combination $\left(11.1 \mathrm{MBq} \text { of }{ }^{188} \text { Re-IDA-D-[c(RGDfK) }\right]_{2}$ with $2 \mathrm{mgkg}^{-1}$ of TMZ) for 2 weeks ( $n=4$ for each). (A) Schematic protocol of the treatment. (B) Tumor volume at each time point. (C) Microvessel and integrin $\alpha_{\mathrm{v}} \beta_{3}$ positive \% area of tumors treated in all tested experimental groups after 2 weeks. (D) Immunohistochemical staining of tumor slices with anti- $\alpha_{v} \beta_{3}$, anti-CD31, and $\gamma \mathrm{H} 2 \mathrm{AX}$ in tumor sections of all tested experimental groups after 2 weeks. Data were analyzed by ANOVA test and post hoc test (Bonferroni correction, $\left.{ }^{*} p<0.05,{ }^{* *} p<0.01,{ }^{* * *} p<0.001,{ }^{* * * *} p<0.0001\right)$. Abbreviation: NSD means no significant difference.

\section{Discussion}

In this study, we demonstrated that ${ }^{99 \mathrm{~m}} \mathrm{Tc}-\mathrm{IDA}-\mathrm{D}-[\mathrm{c}(\mathrm{RGDfK})]_{2}$ SPECT could perform the role of diagnostics and assess integrin $\alpha_{\mathrm{v}} \beta_{3}$ target density changes during treatment with ${ }^{188}$ Re-IDA-D-[c(RGDfK) $]_{2}$ in U87-MG-bearing mice. ${ }^{99 \mathrm{~m}}$ Tc-IDA-D-[c(RGDfK) $]_{2}$ SPECT might be helpful not only for selecting individuals for RGD peptide-based treatment but also for evaluating any changes in integrin $\alpha_{\mathrm{v}} \beta_{3}$ levels and presumably in tumor size after anti-angiogenic treatment. Our preclinical and clinical results suggest that ${ }^{99 \mathrm{~m}} \mathrm{Tc}-\mathrm{IDA}-\mathrm{D}-$ $[c(\text { RGDfK })]_{2}$ could be a novel radiopharmaceutical medical tool. 
Based on our previous findings on ${ }^{188}$ Re-IDA-D-[c(RGDfK) $]_{2}$ accumulation in tumor $\left(12.3 \pm 1.7 \% \mathrm{IDg}^{-1}\right.$ at 30 min post-injection) [18], we performed an integrin-targeted radionuclide therapy using ${ }^{188}$ Re-IDA-D-[c(RGDfK) $]_{2}$ in the U87-MG xenograft model. Several previous studies have performed radiotherapy in a subcutaneous mouse xenograft using ${ }^{177} \mathrm{Lu},{ }^{90} \mathrm{Yo}$, or ${ }^{67} \mathrm{Cu}$-labeled RGD peptide and reported their low therapeutic efficacy and requirement in multiple injections of even high doses (37 MBq) [16,31,32]. However, our current findings indicated that ${ }^{188}$ Re-IDA-D-[c(RGDfK) $]_{2}$ effectively suppressed tumor growth, presumably by destroying integrin with Re- 188 beta emission. Furthermore, the radioactivity $(11.1 \mathrm{MBq})$ used in the present study was relatively low $\left(0.018 \mathrm{MBqg}^{-1}\right)$ and could be appropriate for clinical application. Nonetheless, multiple injections of ${ }^{188} \mathrm{Re}$-IDA$\mathrm{D}-[\mathrm{c}(\text { RGDfK })]_{2}$ were required every $4 \mathrm{~d}$, and thus, further optimization of radiotherapy is needed along with a detailed toxicity test. Moreover, although the antitumor efficacy results found using the subcutaneous tumor model are better than those obtained by $[16,31,32]$, a further criticality of this work could lie in not having used an orthotopic model to be able to explore the BBB crossing ability of our system. However, this aspect will be explored in the future.

Although angiogenesis plays a critical role in tumor growth, it is uncertain whether the PRRT of ${ }^{188}$ Re-IDA-D-[c(RGDfK) $]_{2}$ could be considered a direct cancer therapy. TMZ is an FDA-approved DNA alkylation agent that typically improves survival rates in glioblastoma patients. Since ${ }^{188}$ Re-IDA-D-[c(RGDfK) $]_{2}$ and TMZ have different mechanisms of actions and stoichiometric ratios, we hypothesized that their combination might have a synergistic effect in the treatment of glioma cancer. Reported combination studies show that relatively low doses of the TMZ regime ( $<7 \mathrm{mgkg}^{-1}$, once a week) were effective in the reduction in tumor growth of U87-MG xenografts [33,34]. In our study, we selected the 2 and $5 \mathrm{mgkg}^{-1}$ doses for the TMZ single treatment by considering the incidence of adverse effects related to TMZ. Moreover, we performed PRRT combined with the lower one of these two TMZ doses for the purpose of suggesting that a relatively low dose of TMZ could show an inhibition effect of tumor growth in combination therapy.

Glioblastoma growth is closely associated with the formation of new vessels. In the early stages of glioma development, there is no apparent disruption of the BBB; tumor own vasculature has not yet been formed, and the tumor mass is sustained by normal brain vessels. As glioma progresses and aggravates, endothelial cells derived from normal vessels are roughly separated from the vessel main structure and form new angiogenic spots associated with the tumor site. In this context, the importance of our findings about the combined effect of $2 \mathrm{mg}$ TMZ with the radionuclide emerges, since giving the best therapeutic output in the treatment of angiogenic depletion with glioblastoma progress retardation enables keeping the blood-brain barrier intact and thus avoiding progression of the disease [35].

Compared with the relatively inadequate blocking response of cold Re-RGD peptide in integrin receptors (Figure 2), treatment with ${ }^{188}$ Re-IDA-D-[c(RGDfK) $]_{2}$ had a very significant effect on tumor growth in the U87-MG xenograft model, even at relatively small doses (3.7 MBq). Beta irradiation from RGD peptide inhibited tumor growth, presumably by suppressing angiogenesis and destroying integrin $\alpha_{\mathrm{v}} \beta_{3}$ in the tumor. In addition, ${ }^{188} \mathrm{Re}-$ IDA-D-[c(RGDfK) $]_{2}$ bound to integrin $\alpha_{v} \beta_{3}$ had a crossfire effect that led to DNA damage with subsequent tumor cell death (Figure $3 \mathrm{E}$ ). Consequently, our current findings indicated that ${ }^{188}$ Re-IDA-D-[c(RGDfK) $]_{2}$ was an effective integrin-targeted radiotherapy.

The most important issue in targeted radiotherapy is the selection of agents that will provide optimal treatment efficacy with minimum undesired side effects due to ineffective exposure. While agent selection is nominally based on tissue type or tumor selectivity, it is impossible to predict its effectiveness in cases of multiple lesions or new tumors at different sites. Therefore, it is desirable to combine similar radiotherapeutic agents and evaluate their behavior for specific localization of a particular tumor target. In the present study, we demonstrated an integrated radiodiagnostic and radiotherapeutic agent set. ${ }^{99 \mathrm{~m}}$ Tc-IDA-D-[c(RGDfK) $]_{2}$ was used to evaluate the possible extent of tumor localization 
through binding to a tumor-specific integrin $\alpha_{\mathrm{V}} \beta_{3}$ target and further assess the change in integrin $\alpha_{\mathrm{v}} \beta_{3}$ target density during treatment with ${ }^{188}$ Re-IDA-D-[c(RGDfK) $]_{2}$ (Figure 4A). Our results showed that ${ }^{99 \mathrm{~m}}$ Tc-IDA-D-[c(RGDfK) $]_{2}$ SPECT might be useful not only for selecting individuals for RGD peptide-based treatment but also for evaluating changes in integrin $\alpha_{v} \beta_{3}$ levels and presumably tumor size after radiotherapeutic treatment. While ${ }^{188}$ Re-IDA-D-[c(RGDfK) $]_{2}$ provides the possibility of using integrin-targeted radiotherapy in tumors, there are several limitations to our study. First, we used multiple injections of ${ }^{188}$ Re-IDA-D-[c(RGDfK) $]_{2}$ every $4 \mathrm{~d}$ because of the in vivo rapid clearance of RGD peptide. Second, our in vivo efficacy studies did not include any toxicity test, and the safety of radiotherapy was only estimated by the mouse body weight. Although ${ }^{188}$ Re-IDA-D$[c(\text { RGDfK })]_{2}$ showed a potential PRRT for tumor angiogenesis, special care such as with the kidneys and liver function test panel assay is required to prevent renal and hepatic toxicity. Third, we used only U87-MG glioblastoma cells over a $14 \mathrm{~d}$ treatment period. Future studies should be performed in complementary glioma models for a longer period.

The present study suggested that the combination of PRRT and TMZ might be an effective and synergistic glioblastoma treatment. Internal radiotherapy of tumor angiogenesis combined with chemotherapy and angiogenesis imaging could help to successfully develop new anti-angiogenesis drugs. Further studies examining the efficacy of combined therapy in other glioma models are needed to confirm whether ${ }^{188}$ Re-IDA-D-[c(RGDfK) $]_{2}$ can improve the treatment of GBM.

\section{Conclusions}

In conclusion, the results of biodistribution, pharmacokinetics, in vivo SPECT imaging, and anti-angiogenic radiotherapy efficacy studies suggest that ${ }^{99 \mathrm{~m}} \mathrm{Tc}-$ and ${ }^{188}$ Re-IDA-D$[c(R G D f K)]_{2}$ are promising theranostic tools in the field of tumor-induced angiogenesis. Combined therapy with PRRT and TMZ showed more cytotoxic effects than monotherapy. Overall, ${ }^{188}$ Re-IDA-D-[c(RGDfK) $]_{2}$ might be a valuable and innovative radiotherapeutic agent for the treatment of GBM.

Supplementary Materials: The following are available online at https:/ /www.mdpi.com/article/10 .3390/cancers13195029/s1, Figure S1: Comparison of methods for measuring of tumor volume and radionuclide uptake, Figure S2: A preliminary experiment of ${ }^{188}$ Re-IDA-D-[c(RGDfK) $]_{2}$ treatments, Figure S3: Immunofluorescence images with Q-dot 605-D-[c(RGDfK) $]_{2}$.

Author Contributions: Conceptualization, S.E.K. and B.C.L.; methodology, J.H.J., I.H.S. and J.Y.C.; formal analysis, S.H.L. and H.S.P.; investigation, S.H.L., J.H.J. and I.H.S.; data curation, S.H.L., H.S.P. and F.L.; writing-original draft preparation, S.H.L. and J.Y.C.; writing—review and editing, B.C.L., F.L. and N.D.; supervision, B.C.L. and S.E.K.; funding acquisition, B.C.L. and S.E.K. All authors have read and agreed to the published version of the manuscript.

Funding: This work was supported by Seoul National University Research Grant in 2020, grants from the National Research Foundation of Korea (NRF) (grant No. NRF2021R1A2C2003301 and NRF2021M2E7A1079213) and the SNUBH Research Fund (grants No. 14-2020-009 and 02-2020-003).

Institutional Review Board Statement: The Animal Ethics Committee of Seoul National University Bundang Hospital approved the research protocol (IACUC No. BA1211-117/080-01).

Informed Consent Statement: Not applicable.

Data Availability Statement: All data are contained within the article or the Supplementary Material.

Acknowledgments: The authors are grateful to Enviro Korea Co., Ltd. for providing the ${ }^{188}$ Re generator.

Conflicts of Interest: The authors declare no conflict of interest.

\section{References}

1. Folkman, J. Role of angiogenesis in tumor growth and metastasis. Semin. Oncol. 2002, 29, 15-18. [CrossRef] [PubMed]

2. Backer, M.V.; Backer, J.M. Imaging Key Biomarkers of Tumor Angiogenesis. Theranostics 2012, 2, 502-515. [CrossRef] [PubMed]

3. Ruoslahti, E. Specialization of tumour vasculature. Nat. Rev. Cancer 2002, 2, 83-90. [CrossRef] [PubMed] 
4. $\quad$ Brooks, P.C.; Montgomery, A.M.P.; Rosenfeld, M.; Reisfeld, R.A.; Hu, T.; Klier, G.; Cheresh, D.A. Integrin $\alpha_{\mathrm{v}} \beta_{3}$ antagonists promote tumor regression by inducing apoptosis of angiogenic blood vessels. Cell 1994, 79, 1157-1164. [CrossRef]

5. Kerbel, R.; Folkman, J. Clinical translation of angiogenesis inhibitors. Nat. Rev. Cancer 2002, 2, 727-739. [CrossRef]

6. Fass, L. Imaging and cancer: A review. Mol. Oncol. 2008, 2, 115-152. [CrossRef]

7. Haubner, R.; Wester, H.J.; Weber, W.A.; Mang, C.; Ziegler, S.I.; Goodman, S.L.; Senekowitsch-Schmidtke, R.; Kessler, H.; Schwaiger, M. Noninvasive Imaging of $\alpha_{\mathrm{v}} \beta_{3}$ Integrin Expression Using ${ }^{18}$ F-labeled RGD-containing Glycopeptide and Positron Emission Tomography. Cancer Res. 2001, 61, 1781-1785.

8. Zhang, X.; Xiong, Z.; Wu, Y.; Cai, W.; Tseng, J.R.; Gambhir, S.S.; Chen, X. Quantitative PET Imaging of Tumor Integrin $\alpha_{\mathrm{v}} \beta_{3}$ Expression with ${ }^{18}$ F-FRGD 2 . J. Nucl. Med. 2006, 47, 113-121.

9. McParland, B.J.; Miller, M.P.; Spinks, T.J.; Kenny, L.M.; Osman, S.; Khela, M.K.; Aboagye, E.; Coombes, R.C.; Hui, A.M.; Cohen, P.S The Biodistribution and Radiation Dosimetry of the Arg-Gly-Asp Peptide ${ }^{18}$ F-AH111585 in Healthy Volunteers. J. Nucl. Med. 2008, 49, 1664-1667. [CrossRef]

10. Shi, J.; Kim, Y.S.; Zhai, S.; Liu, Z.; Chen, X.; Liu, S. Improving Tumor Uptake and Pharmacokinetics of ${ }^{64}$ Cu-Labeled Cyclic RGD Peptide Dimers with $\mathrm{Gly}_{3}$ and $\mathrm{PEG}_{4}$ Linkers. Bioconjugate Chem. 2009, 20, 750-759. [CrossRef]

11. Janssen, M.L.; Oyen, W.J.; Dijkgraaf, I.; Massuger, L.F.; Frielink, C.; Edwards, D.S.; Rajopadhye, M.; Boonstra, H.; Corstens, F.H.; Boerman, O.C. Tumor Targeting with Radiolabeled $\alpha_{\mathrm{v}} \beta_{3}$ Integrin Binding Peptides in a Nude Mouse Model. Cancer Res. 2002, 62, 6146-6151.

12. Lee, B.C.; Sung, H.J.; Kim, J.S.; Jung, K.H.; Choe, Y.S.; Lee, K.H.; Chi, D.Y. Synthesis of Tc-99m labeled glucosamino-Aspcyclic(Arg-Gly-Asp-D-Phe-Lys) as a potential angiogenesis imaging agent. Bioorg. Med. Chem. 2007, 15, 7755-7764. [CrossRef]

13. Indrevoll, B.; Kindberg, G.M.; Solbakken, M.; Bjurgert, E.; Johansen, J.H.; Karlsen, H.; Mendizabal, M.; Cuthbertson, A. NC-100717: A versatile RGD peptide scaffold for angiogenesis imaging. Bioorg. Med. Chem. Lett. 2006, 16, 6190-6193. [CrossRef] [PubMed]

14. Jia, B.; Liu, Z.; Zhu, Z.; Shi, J.; Jin, X.; Zhao, H.; Li, F.; Liu, S.; Wang, F. Blood Clearance Kinetics, Biodistribution, and Radiation Dosimetry of a Kit-Formulated Integrin $\alpha_{\mathrm{v}} \beta_{3}$-Selective Radiotracer ${ }^{99 \mathrm{~m}} \mathrm{Tc}-3 \mathrm{PRGD}_{2}$ in Non-Human Primates. Mol. Imaging Biol. 2011, 13, 730-736. [CrossRef] [PubMed]

15. Lucente, E.; Liu, H.; Liu, Y.; Hu, X.; Lacivita, E.; Leopoldo, M.; Cheng, Z. Novel ${ }^{64}$ Cu Labeled RGD 2 -BBN Heterotrimers for PET imaging of Prostate Cancer. Bioconjugate Chem. 2018, 29, 1595-1604. [CrossRef]

16. Jiang, L.; Miao, Z.; Liu, H.; Ren, G.; Bao, A.; Cutler, C.S.; Shi, H.; Cheng, Z. ${ }^{177}$ Lu-labeled RGD-BBN heterodimeric peptide for targeting prostate carcinoma. Nucl. Med. Commun. 2013, 34, 909-914. [CrossRef]

17. Liu, Z.; Radtke, M.A.; Wong, M.Q.; Lin, K.-S.; Yapp, D.T.; Perrin, D.M. Dual Mode Fluorescent ${ }^{18}$ F-PET Tracers: Efficient Modular Synthesis of Rhodamin-[cRGD $]_{2}-\left[{ }^{18} \mathrm{~F}\right]$-Organotrifluoroborate, Rapid, and High Yielding One-Step ${ }^{18}$ F-Labeling at High Specific Activity, and Correlated in Vivo PET Imaging and ex Vivo Fluorescence. Bioconjugate Chem. 2014, 25, 1951-1962. [CrossRef] [PubMed]

18. Lee, B.C.; Moon, B.S.; Kim, J.S.; Jung, J.H.; Park, H.S.; Katzenellenbogen, J.A.; Kim, S.E. Synthesis and biological evaluation of RGD peptides with the ${ }^{99 \mathrm{~m}} \mathrm{Tc} /{ }^{188}$ Re chelated iminodiacetate core: Highly enhanced uptake and excretion kinetics of theranostics against tumor angiogenesis. RSC Adv. 2013, 3, 782-792. [CrossRef]

19. Hardee, M.E.; Zagzag, D. Mechanisms of Glioma-Associated Neovascularization. Am. J. Pathol. 2012, 181, 1126-1141. [CrossRef] [PubMed]

20. Chaudhry, I.H.; O’Donovan, D.G.; Brenchley, P.E.C.; Reid, H.; Roberts, I.S.D. Vascular endothelial growth factor expression correlates with tumour grade and vascularity in gliomas. Histopathology 2001, 39, 409-415. [CrossRef]

21. Lamszus, K.; Ulbricht, U.; Matschke, J.; Brockmann, M.A.; Fillbrandt, R.; Westphal, M. Levels of soluble vascular endothelial growth factor (VEGF) receptor 1 in astrocytic tumors and its relation to malignancy, vascularity, and VEGF-A. Clin. Cancer Res. 2003, 9, 1399-1405.

22. Song, Y.S.; Park, H.S.; Lee, B.C.; Jung, J.H.; Lee, H.Y.; Kim, S.E. Imaging of integrin $\alpha_{v} \beta_{3}$ expression in lung cancers and brain tumors using single-photon emission computed tomography with a novel radiotracer ${ }^{99 \mathrm{~m}} \mathrm{Tc}-\mathrm{IDA}-\mathrm{D}-[\mathrm{c}(\mathrm{RGDfK})]_{2}$. Cancer Biother. Radiopharm. 2017, 32, 288-296. [CrossRef]

23. Song, Y.S.; Kim, J.H.; Lee, B.C.; Jung, J.H.; Park, H.S.; Kim, S.E. Biodistribution and Internal Radiation Dosimetry of ${ }^{99 m}$ Tc-IDA-D$[\mathrm{c}(\mathrm{RGDfK})]_{2}$ (BIK-505), a Novel SPECT Radiotracer for the Imaging of Integrin $\alpha_{\mathrm{v}} \beta_{3}$ Expression. Cancer Biother. Radiopharm. 2018, 33, 396-402. [CrossRef]

24. Yoo, J.S.; Lee, J.; Jung, J.H.; Moon, B.S.; Kim, S.; Lee, B.C.; Kim, S.E. SPECT/CT Imaging of High-Risk Atherosclerotic Plaques using Integrin-Binding RGD Dimer Peptides. Sci. Rep. 2015, 5, 11752.

25. Mancuso, M.R.; Davis, R.; Norberg, S.M.; O’Brien, S.; Sennino, B.; Nakahara, T.; Yao, V.J.; Inai, T.; Brooks, P.; Freimark, B.; et al. Rapid vascular regrowth in tumors after reversal of VEGF inhibition. J. Clin. Investig. 2006, 116, 2610-2621. [CrossRef]

26. Inai, T.; Mancuso, M.; Hashizume, H.; Baffert, F.; Haskell, A.; Baluk, P.; Hu-Lowe, D.D.; Shalinsky, D.R.; Thurston, G.; Yancopoulos, G.D.; et al. Inhibition of Vascular Endothelial Growth Factor (VEGF) Signaling in Cancer Causes Loss of Endothelial Fenestrations, Regression of Tumor Vessels, and Appearance of Basement Membrane Ghosts. Am. J. Pathol. 2004, 165, 35-52. [CrossRef]

27. Henno, S.; Lambotte, J.C.; Glez, D.; Guigand, M.; Lancien, G.; Cathelineau, G. Characterisation and quantification of angiogenesis in $\beta$-tricalcium phosphate implants by immunohistochemistry and transmission electron microscopy. Biomaterials 2003, 24, 3173-3181. [CrossRef] 
28. Liu, Z.; Shi, J.; Jia, B.; Yu, Z.; Liu, Y.; Zhao, H.; Li, F.; Tian, J.; Chen, X.; Liu, S.; et al. Two ${ }^{90}$ Y-Labeled Multimeric RGD Peptides RGD4 and 3PRGD 2 for Integrin Targeted Radionuclide Therapy. Mol. Pharm. 2011, 8, 591-599. [CrossRef]

29. Lucie, S.; Elisabeth, G.; Stéphanie, F.; Guy, S.; Amandine, H.; Corinne, A.R.; Didier, B.; Catherine, S.; Alexei, G.; Pascal, D.; et al. Clustering and Internalization of Integrin $\alpha_{v} \beta_{3}$ With a Tetrameric RGD-synthetic Peptide. Mol. Ther. 2009, 17, 837-843. [CrossRef] [PubMed]

30. Bourton, E.C.; Plowman, P.N.; Smith, D.; Arlett, C.F.; Parris, C.N. Prolonged expression of the $\gamma$-H2AX DNA repair biomarker correlates with excess acute and chronic toxicity from radiotherapy treatment. Int. J. Cancer 2011, 129, 2928-2934. [CrossRef] [PubMed]

31. Janssen, M.; Frielink, C.; Dijkgraaf, I.; Oyen, W.; Edwards, D.S.; Liu, S.; Rajopadhye, M.; Massuger, L.; Corstens, F.; Boerman, O. Improved Tumor Targeting of Radiolabeled RGD Peptides Using Rapid Dose Fractionation. Cancer Biother. Radiopharm. 2004, 19, 399-404. [PubMed]

32. Jin, Z.-H.; Furukawa, T.; Ohya, T.; Degardin, M.; Sugyo, A.; Tsuji, A.B.; Fujibayashi, Y.; Zhang, M.-R.; Higashi, T.; Boturyn, D.; et al ${ }^{67} \mathrm{Cu}$-Radiolabeling of a multimeric RGD peptide for $\alpha_{v} \beta_{3}$ integrin-targeted radionuclide therapy: Stability, therapeutic efficacy, and safety studies in mice. Nucl. Med. Commun. 2017, 38, 347-355. [CrossRef]

33. Jun, H.T.; Sun, J.; Rex, K.; Radinsky, R.; Kendall, R.; Coxon, A.; Burgess, T.L. AMG 102, A Fully Human Anti-Hepatoxyte Growth Factor/Scatter Factor Neutralizing Antibody, Enhances the Efficacy of Temozolomide or Docetaxel in U-87 MG Cells and Xenografts. Clin. Cancer Res. 2007, 13, 6735-6742. [CrossRef] [PubMed]

34. Johns, T.G.; Luwor, R.B.; Murone, C.; Walker, F.; Weinstock, J.; Vitali, A.A.; Perera, R.M.; Jungbluth, A.A.; Stockert, E.; Old, L.J.; et al. Antitumor efficacy of cytotoxic drugs and the monoclonal antibody 806 is enhanced by the EGF receptor inhibitor AG1478. Proc. Natl. Acad. Sci. USA 2003, 100, 15871-15876. [CrossRef]

35. Dubois, L.G.; Campanati, L.; Righy, C.; D'Andrea-Meira, I.; Spohr, T.C.L.; Porto-Carreiro, I.; Pereira, C.M.; Balca-Silva, J.; Kahn, S.A.; Dos Santos, M.F.; et al. Gliomas and the vascular fragility of the blood brain barrier. Front. Cell. Neurosci. 2014, 12, 418. [CrossRef] [PubMed] 